\title{
User Perception of Media Content Association in Olfaction- enhanced Multimedia
}

\author{
GHEORGHITA GHINEA AND OLUWAKEMI ADEMOYE, Brunel University
}

\begin{abstract}
Olfaction is an exciting challenge facing multimedia applications. In this paper we have investigated the user perception of the association between olfactory media content and video media content in olfactory-enhanced multimedia. Results show that that the association between scent and content has a significant impact on the user-perceived experience of olfactory-enhanced multimedia.

Categories and Subject Descriptors: H.1.2 [User/Machine Systems]: Human factors; H.5.1 [Multimedia Information Systems]: Artificial, augmented, and virtual realities; H.5.2 [Information Interfaces and Presentation]: User InterfacesEvaluation/methodology

General Terms: Design, Experimentation, Human Factors

Additional Key Words and Phrases: olfaction, human-computer interaction, multimedia quality, quality of perception
\end{abstract}

\section{ACM Reference Format:}

Ghinea, G. and Ademoye, A. 2011. Neural Modeling of Flow Rendering Effectiveness. ACM Trans. Multimedia Comput. Commun. Appl. -. 2, 3, -, Article - (January 2011), 20 pages..

$\mathrm{DOI}=10.1145 / 0000000.0000000$ http://doi.acm.org/10.1145/0000000.0000000

\section{INTRODUCTION}

At the fundamental core of multimedia applications is the use of multiple media objects that are correlated in some way or another in order to reach out to users on an informational, entertainment or infotainment level. In this way, information may be conveyed by the relationship between the combined media objects, as well as by the individual media objects (Rowe and Jain, 2005). As such, when associating computer generated smell with audiovisual content to create an olfaction-enhanced multimedia experience for users, there is a tendency to emit scents that are directly correlated and relevant to the content they are being associated with. However, in entertainment and infotainment multimedia applications, it might be possible that users will just appreciate the novelty factor of integrating scents with multimedia applications, and that the actual scent being emitted might not be of importance. Moreover, it might also be that users would not mind what scent is being emitted as long as it is "close" to the one that matches their expectations. As a result, in this paper, we aim to answer the following research question: 'does the correct association of scent and content enhance the user experience of multimedia applications?

Accordingly in this paper, we present the results of an empirical study carried out to discover if the correct association of scent and content is important when augmenting multimedia applications with computer generated scent. The paper is structured as follows: in section 2, we introduce the user to related scented media work, while sections 3 and 4 present the details of our experimental methodology and the results of our experiment respectively. Lastly, section 5 discusses our conclusions.

\section{RELATED WORK}

Combining artificially generated scent with audiovisual content in order to enhance the meaning of userpresented information started in the 20th century. Although, the idea was not found widely acceptable or

Authors' address: G. Ghinea, Department of Information Systems and Computing, Brunel University, Kingston Lane, Uxbridge, UB8 3PH; email: george.ghinea@brunel.ac.uk; Oluwkemi A Ademoye, Department of Information Systems and Computing, Brunel University, Kingston Lane, Uxbridge, UB8 3PH; email: kademoye@yahoo.com

Permission to make digital or hardcopies of part or all of this work for personal or classroom use is granted without fee provided that copies are not made or distributed for profit or commercial advantage and that copies show this notice on the first page or initial screen of a display along with the full citation. Copyrights for components of this work owned by others than ACM must be honored. Abstracting with credits permitted. To copy otherwise, to republish, to post on servers, to redistribute to lists, or to use any component of this work in other works requires prior specific permission and/or a fee. Permissions may be requested from Publications Dept., ACM, Inc., 2 Penn Plaza, Suite 701, New York, NY 10121-0701 USA, fax +1 (212) 869-0481, or permissions@acm.org.

@2011 ACM 1544-3558/2010/05-ART1 \$10.00

DOI10.1145/0000000.0000000 http://doi.acm.org/10.1145/0000000.0000000 
particularly appealing to users back then, these earlier attempts at creating olfaction-enhanced audiovisual presentations provide enlightening and interesting background into this research area.

The downfall of these earlier attempts may largely be attributed to the technology used, or to be more exact, the lack of appropriate technology to emit scheduled scents and in controlled amounts. Nonetheless, several years later with great advancements in technology, olfaction-enhanced multimedia is still a challenging research area. Consequently, even the more recent attempts at creating olfaction-enhanced multimedia systems and displays have faced challenges of their own, with the result being that progress is still nowhere near as advanced as one would expect. Nonetheless, there have been some significant developments in recent times and in the following we summarize the more significant of these.

\subsection{Scented Media in Computing}

The relative scarcity of commercially available olfactory data generating devices has certainly contributed to the slow progress of the use of olfaction in computing. However, a further hindrance stems from the fact that whilst it is usually easy to combine other data formats (e.g. sound and video) to produce a desired output mix, this is extremely difficult to do with olfactory data as a standard additive process or model for combining different scents does not exist. Consequently, more often than not smell generating devices are limited to producing the specific smells that have been loaded into their respective storage systems. Nonetheless, there has been some olfactory data usage in the computing field over the years, with a number of researchers building their own computer generating smell systems (Boyd et al., 2006; Kaye, 2001) and others relying on the few that are commercially available. More recently, Nakamoto et al. (2008) have developed a smell generating device which works by combining chemicals to produce the desired scents as and when required, but this device is also not yet commercially available and still under research development.

The areas of computing that have experienced significant usage of olfactory data over the years include virtual reality (Jones et al., 2004; Nakamoto, 2005a,b; Washburn et al., 2003), multimodal displays (Bodnar et al., 2004; Dinh et al., 1999; Tijou, Richard, \& Richard, 2006) and alerting systems (Bodnar et al., 2004; Brewster et al., 2006), and media and entertainment systems (Boyd et al., 2006; Fragra, 2003; Mochizuki et al., 2004; Nakamoto et al., 2008). At the forefront are the research efforts of Kaye (2001, 2004), which focused extensively on the practicality of using computer generated smell in computing and creating an awareness of the issues, problems and limitations, associated with the use of olfactory data and particularly for scented media displays.

\subsection{Unrelated Association of Scents with other Media Content}

In most of the research studies mentioned above, the association of olfactory data with other media objects has been such that the emitted scents are directly correlated and relevant to, or at the very least have an abstract relationship with, the content (mostly visual) they are being associated with. The focus of this work is to investigate whether the correct association of scent and content enhances the user experience of multimedia applications, and as such we are also interested in related studies that have carried out comparison analysis between the use of related and unrelated scents in scented media. There have been studies carried out that do use scents that are not directly related to the content that they are associated with, although most of them focus on investigating the effect of visual cues on human olfactory perception, and we review some of these below.

Blackwell (1995) carried out a study on visual cues and their effects on odor assessment. In this study, two sets of experiments were conducted. The first involved identifying the odor of fruit solutions that had been either inappropriately coloured or not. The second experiment required participants to arrange fruit solutions in varying colour intensities in their order of odor intensity, where the variation in colour intensity did not correspond to the variation in odor intensity. A control study was also carried out for the second experiment where the variation of the colour intensity of the fruit solutions corresponded to the variations of its odor intensity. The findings from these two different experiments indicate that generally participants found it difficult to ignore the visual cues present and their associations with the odors. Moreover, when the stimuli given to two different senses are conflicting, analysis is difficult for the user. Experiment 1 showed that the identification of odors proved significantly more difficult when presented with an inappropriate colour of the fruit solution, whilst Experiment 2 showed that more subjects ranked the samples in the correct order when the colour intensity and odor strengths were compatible rather than when they were conflicting. 
Morrot et al. (2001) carried out a similar study to investigate the interaction between the vision of colours and odor determination, but through the lexical analysis of wine experts' tasting comments. For the experiment, they simulate a wine tasting practice, where the wine tasters provide comments on the tasted wines based on the visual, olfactory and gustatory properties of the wines. A previous study (Williams et al. in Morrot et al., 2001) had shown that perception of the olfactory qualities of wines changes depending on whether the colour of the wine is visible or hidden from the subjects by using transparent and opaque wine glasses respectively. In the study carried out by Morrot et al. (2001), they coloured a white wine artificially red and presented it to wine experts to analyse, alongside the uncoloured white wine and a red wine. To confirm that the colorant used to artificially colour the wine had no influence on the coloured wine, a pretest experiment was carried out to confirm that the white wine and its artificially coloured version were perceived as the same when its colour was obscured from the tasters. Their results showed that the white wine was perceived as having the odor of a red wine when coloured red (all of the wine tasters that participated in the study described the artificially coloured wine with terms relating to red wine qualities; the wine's colour thus appears to provide significant sensory information, which misleads the subjects' ability to judge flavour; lastly, the mistake is stronger in the presence than in the absence of access to the wine colour).

Gottfried and Dolan (2003) carried out a study to characterise the mechanisms underlying visual modulation of olfactory perception. Although this study is more concerned with observing the activity of the olfactory function within the brain to confirm the findings from their study, they also report on the human perceptual findings and it is these that we highlight here. Participants in this study participated in a simple olfactory detection task, in which they were presented with odors alone or the odors combined with either semantically congruent pictures or with semantically incongruent pictures. The findings from their study showed that although odor detection was faster and more accurate when odors appeared in the context of semantically congruent visual cues, the behavioural findings show that the mere presentation of a visual cue is insufficient to facilitate olfactory perception. Instead, the effect critically relies on access to semantically concordant information.

Sakai et al. (2005) mention a previous study that they carried out to investigate the effect of visual colour on human olfactory perception before presenting their current study on the effect of visual images on the perception of odors. The previous study involved participants engaged in a simple exercise to identify a cola-flavoured solution and an orange-flavoured solution. Findings from the study showed that all participants correctly identified the cola-flavoured and orange-flavoured solutions when they were coloured brown and orange respectively, but misidentified them when they were respectively coloured orange and brown. The cola-flavoured solution was mostly identified as being orange or tea when coloured orange, whilst the orange-flavoured solution was identified as being tea or a grape-flavoured solution when coloured dark brown.

More recently, in addition to reviewing the literature on effects of vision (colour and images) on olfactory perception, Sakai et al. (2005) report on a study they have conducted that involved participants evaluating the intensity of, and their preference for, an odor when presented with two kinds of visual images. The first image, which the participant had previously identified as being the most appropriate image to accompany the odor (Image X), and the second which they had selected as being inappropriate for the odor (Image Y). In addition, participants were required to rate odors as being desirable or not. The findings from their study suggest that the use of appropriate pictures enhances the evaluation of odor preference as preference ratings for odors rated as preferable in the preliminary selection phase were significantly higher when they were presented with Image $X$ than those presented with Image $Y$. On the other hand, preference ratings for odors rated as being undesirable in the preliminary selection phase showed a lower preference rating when paired with Image $X$ than when paired with Image $Y$. They conclude that while it is conceivable that associations between vision and olfaction in our daily lives also develop visual images for odors, the association between visual images and odors still remains unclear.

When talking about user perception of mismatched odors with visual cues, an interesting incident worth mentioning is the experiment described by Kaye (2001) that was carried out by Granada Television, UK. Television viewers were told that a tone corresponding to a particular smell (which they were told would be a non-manure country smell) would be played during a show and they should call or write in if they smelt anything or in particular if they did not perceive the odor. The following morning the same instructions were repeated for a radio show and the same tone was played.

Interestingly, the results of this experiment extracted from Kaye [see Kaye (2001) for more details] were as follows: 179 responses were received in connection to the television broadcast and 43 in connection 
with the radio broadcast. 37/179 reported 'hay', 27/179 reported 'grass', and so on for the television broadcast, with 24/179 reporting that no smell was perceived. And for the radio broadcast, 21/43 reported that no smell was perceived. The resulting perceptions of the viewers and listeners that detected odors in this experiment can best be described by what is referred to as olfactory imagery (Djordjevic et al., 2004; Stevenson and Case, 2005), which is the ability to imagine an odor and then to be able to subsequently conjure up the actual sensation of perceiving that odor even though the odor is absent from the atmospheric surroundings. Obviously, the fact that the organisers had mentioned that the scent was going to be a non-manure country smell, had already provided the viewers with some form of mental image in their minds. Incidentally, there are several researchers who do not believe in the existence of imagery for the olfactory sense as many people say that they cannot imagine odors no matter how hard they try (Djordjevic et al., 2004; Stevenson and Case, 2005).

All aforementioned studies have highlighted that the use of olfaction in scented multimedia is still a challenging research area. These studies on the unrelated association of scents with other media content, which mostly focused on the effect of visual cues on odor identification, have highlighted the fact that indeed our visual sense does play an important role in human olfactory perception. However, the interest of this research lies with what effect, if any, the correct association between visual content and scents in olfaction-enhanced multimedia displays has on a users' sense of enjoyment or the sense of reality, especially when applied to applications that are aimed at creating a more immersive, multi-sensory experience for the user. In the following section, we present the results of an exploratory study that we have conducted to find out if the unrelated association of visual and olfactory cues does indeed have any effect on these.

\section{EXPERIMENTAL METHODOLOGY}

\subsection{Participants}

A total of fifty participants, 21 males and 29 females between the ages of 18 and 38, from a wide variety of backgrounds, took part in the study. Potential participants were asked if they had undergone any smell recognition training, and if they responded in the affirmative, they were not allowed to participate in the experiment. Potential participants also suffering from colds, or any other conditions that might have impaired their sense of smell were also stopped from participating in the study, or asked to return at a later date when their sense of smell was no longer impaired if they so wished. Participants were not offered any incentives to take part in any of the investigative studies and they were also allowed to opt out of the experiment at any point in time during the course of the experiment. Once recruited and vetted, participants were randomly split into two groups, an experimental study group and a control study group, each made up of 25 participants.

\subsection{Experimental Materials}

We used the Vortex Active device to dispense olfactory data during our experiments. This is a line-of-sight device, which was mounted at an angle to and approximately half a metre from the participant's nose. We adopted this approach because our device was not head-mountable, and moreover, we wanted to create the effect of a natural breeze of scent rather than a choking release. In a pilot study conducted prior to the experiment proper, we also observed that it took about $2 \mathrm{~s}$ for the scent emitted by the Vortex Active device to reach the target users' nose at this distance, which we accordingly factored into our experimental design setup.

The Vortex Active uses fans to disperse scents (Ghinea and Ademoye, in press), commercially available from the manufacturer of the device, Dale Air, as individual scent-impregnated cartridges. Using the Vortex Active's USB fan controller application, we programmed it to emit the required loaded scent at the scheduled time during each video clip playback

As regards the scents themselves, it is advisable that familiar smells be used for experiments involving the use of olfactory data (Kaye, 2001). We finally opted for six smells which distinguish between the odor classes of flowery, foul, fruity, burnt, resinous and spicy. Six video clips, whose content respectively corresponded to the six scents, were used in our study:

- Burnt (Documentary on bush fires in Oklahoma)

- Flowery (News broadcast featuring perfume launch) 
- Foul (Documentary about rotting fruits)

- Fruity (Cookery show on how to make a fruit cocktail)

- Resinous (Documentary on Spring allergies \& Cedar Wood)

- Spicy (Cookery show on how to make chicken curry).

Each clip was shown in a $240 \times 180$ window and was roughly 90 s long, with the duration of the olfactory data lasting for about 30 seconds, in the middle third of the clip. The 30 s duration for the olfactory data was chosen since, as a result of odor adaptation, scents are generally recognizable in the ambient vicinity for a period of 30s (Washburn et al., 2003).

\subsection{Experimental Procedure}

The experimental procedure involved participants watching the set of six video clips augmented with computer generated scent. The olfactory data was varied for each of the six video clips watched so that participants got to watch each video clip with a different smell. After watching a particular olfactionenhanced video clip, each user filled in a questionnaire, as detailed in Figure 1.

\section{Video 1}

1. The smell was released:

$$
\square \text { Too Earty } \square \text { Earty } \square \text { At an Appropriate Time } \square \text { Late } \square \text { Too Late }
$$

2. The smell was relevant to what I was watching:

$$
\square \text { Strongly Disagree } \square \text { Disagree } \quad \square \text { Neither Agree or Disagree } \quad \square \text { Agree } \quad \square \text { Strongly Agree }
$$

3. The smell was distracting:

$\square$ Stronghy Disagree $\square$ Disagree $\quad \square$ Neither Agree or Disagree $\quad \square$ Agree $\quad \square$ Strongly Agree

4. The smell heightened the sense of reality whilst watching the video clip?
$\square$ Strongly Disagree $\square$ Disagree
$\square$ Neither Agree or Disagree $\quad \square$ Agree
$\square$ Strongly Agree

5. The smell was annoying:

$\square$ Stronghy Disagree $\square$ Disagree $\quad \square$ Neither Agree or Disagree $\quad \square$ Agree $\quad \square$ Stronghy Agree

6. I enjoyed watching the video clip?

$\square$ Stronghy Disagree $\square$ Disagree $\quad \square$ Neither Agree or Disagree $\quad \square$ Agree $\quad \square$ Stronghy Agree

7. If you did detect a smell during the video clip, choose which of the following options bes; describes the nature of the smell released during the video clip (please select only one option):
$\square$ stale
$\square$ flowery
$\square$ woody
$\square$ burnt
$\square$ garlicky
$\square$ foul

$\square$ spicy $\square$ fruity $\quad \square$ malty (cereal) $\square$ did not detect any amell

8. If you did detect a smell during the video clip, please tell us in your own words how you would describe what you smelt (could be the name of anything e.g. some object, food item, plant, etc.)?

9. Which of the following categories of smell do you think would have been best suited as the smel released during the video clip (please select ony one option and you can select the same answer chosen for question 7 ;

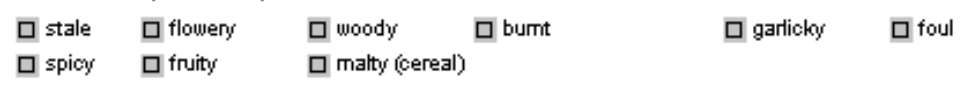

10. Please tell us in your own words what smell you think would have been most appropriate to use in the video clip that you have just watched (please specify only ome smell-the most aporopriate)? Simell: 
Experiments were scheduled and set-up well in advance of participants arriving for the scheduled session in the experimental lab (Figure 2). The door and window in the lab were left open during the setup process to eliminate possible lingering and diffusion effects of the smells escaping from the scent cartridges. In addition, to further eliminate the possibility of smell lingering effects between successive viewings of each of the six video clips, a desktop fan was switched on after each video clip playback while the participant completed the corresponding video clip questionnaire.

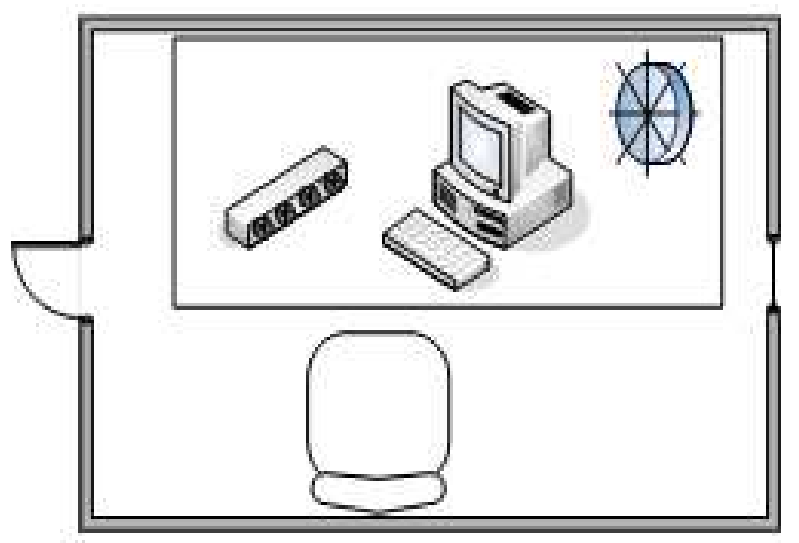

Figure 2 Laboratory Set-up

As mentioned above, participants were split into two study groups. In the experimental group, the twenty-five participants watched the olfaction-enhanced videos with semantically unrelated scent, while for the control study group, the participants watched all of the six olfaction-enhanced videos with the correctly associated scent (i.e. a scent that was semantically related to the audiovisual content of the watched video). Accordingly, the independent variable measured for this experiment was the type of olfactory media content associated with each of the video clips, which varied between semantically related and unrelated olfactory media content.

Table I below shows how the semantically mismatched olfactory data was distributed across participants in the experimental study, with subject case 1 applying to participants 1, 6, 11 and 16, subject case 2 to participants 2, 7, 12 and 17, and so on. The videos viewed by all of the participants in the control study group were synchronized with the semantically correct associated scent as shown in the table. The playback of the videos with each of the predefined associated scents was randomized in order to minimize order effects.

Table I: Summary breakdown of olfactory data associated with audiovisual content assigned to the different subject cases in the experimental and control group studies.

\begin{tabular}{|l|c|l|l|l|l|l|l|}
\hline $\begin{array}{l}\text { Study } \\
\text { Group }\end{array}$ & $\begin{array}{l}\text { Subject } \\
\text { Case }\end{array}$ & $\begin{array}{l}\text { Burnt } \\
\text { Video }\end{array}$ & $\begin{array}{l}\text { Flowery } \\
\text { Video }\end{array}$ & $\begin{array}{l}\text { Fruity } \\
\text { Video }\end{array}$ & $\begin{array}{l}\text { Foul } \\
\text { Video }\end{array}$ & $\begin{array}{l}\text { Resinous } \\
\text { Video }\end{array}$ & $\begin{array}{l}\text { Spicy } \\
\text { Video }\end{array}$ \\
\hline $\begin{array}{l}\text { Experiment } \\
\text { Group }\end{array}$ & 1 & Curry & $\begin{array}{l}\text { Burning } \\
\text { Wood }\end{array}$ & $\begin{array}{l}\text { Wall- } \\
\text { flower }\end{array}$ & $\begin{array}{l}\text { Straw- } \\
\text { berry }\end{array}$ & $\begin{array}{l}\text { Rubbish } \\
\text { Acrid }\end{array}$ & $\begin{array}{l}\text { Cedar } \\
\text { Wood }\end{array}$ \\
\cline { 2 - 7 } & 2 & $\begin{array}{l}\text { Cedar } \\
\text { Wood }\end{array}$ & Curry & $\begin{array}{l}\text { Burning } \\
\text { Wood }\end{array}$ & $\begin{array}{l}\text { Wall- } \\
\text { flower }\end{array}$ & $\begin{array}{l}\text { Straw- } \\
\text { berry }\end{array}$ & $\begin{array}{l}\text { Rubbish } \\
\text { Acrid }\end{array}$ \\
\cline { 2 - 7 } & 3 & $\begin{array}{l}\text { Rubbish } \\
\text { Acrid }\end{array}$ & $\begin{array}{l}\text { Cedar } \\
\text { Wood }\end{array}$ & Curry & $\begin{array}{l}\text { Burning } \\
\text { Wood }\end{array}$ & $\begin{array}{l}\text { Wall- } \\
\text { flower }\end{array}$ & $\begin{array}{l}\text { Straw- } \\
\text { berry }\end{array}$ \\
\cline { 2 - 7 } & 4 & $\begin{array}{l}\text { Straw- } \\
\text { berry }\end{array}$ & $\begin{array}{l}\text { Rubbish } \\
\text { Acrid }\end{array}$ & $\begin{array}{l}\text { Cedar } \\
\text { Wood }\end{array}$ & Curry & $\begin{array}{l}\text { Burning } \\
\text { Wood }\end{array}$ & $\begin{array}{l}\text { Wall- } \\
\text { flower }\end{array}$ \\
\cline { 2 - 7 } & 5 & $\begin{array}{l}\text { Wall- } \\
\text { flower }\end{array}$ & $\begin{array}{l}\text { Straw- } \\
\text { berry }\end{array}$ & $\begin{array}{l}\text { Rubbish } \\
\text { Acrid }\end{array}$ & $\begin{array}{l}\text { Cedar } \\
\text { Wood }\end{array}$ & Curry & $\begin{array}{l}\text { Burning } \\
\text { Wood }\end{array}$ \\
\hline $\begin{array}{l}\text { Control } \\
\text { Group }\end{array}$ & All & $\begin{array}{l}\text { Burning } \\
\text { Wood }\end{array}$ & $\begin{array}{l}\text { Wall- } \\
\text { flower }\end{array}$ & $\begin{array}{l}\text { Straw- } \\
\text { berry }\end{array}$ & $\begin{array}{l}\text { Rubbish } \\
\text { Acrid }\end{array}$ & $\begin{array}{l}\text { Cedar } \\
\text { Wood }\end{array}$ & Curry \\
\hline
\end{tabular}




\section{RESULTS}

The question we set out to answer with the investigative study reported in this paper is, 'does the association of scent and content enhance the user experience of multimedia applications?. To find answers to the specified research question, we will be measuring the impact of incorrectly associating olfactory media content with audiovisual media content on the user-perceived experience of olfactionenhanced multimedia. Findings will be determined from analyzing data collated from participants responses to the questionnaire completed during the investigative study. Moreover, the impact of content association on users' experience of olfaction-enhanced multimedia will be ascertained according to participants' opinions in respect of the following components of the evaluation questionnaire (Figure 1):

- User-perceived experience of the sense of relevance of the olfactory media

- User-perceived experience of the sense of reality of the olfaction-enhanced multimedia

- User acceptability of olfactory media in terms of how distracting they find it

- User-perceived enjoyment of the olfaction-enhanced multimedia experience

As a first step in the analysis of data we ran a Mann-Whitney U-test to establish whether there were any significant differences in the ratings between the control and experimental groups in respect of the above four dimensions of the user experience. This test confirmed that, in all respects, the obtained responses were significantly different between the two user groups (Table II).

Table II Mann-Whitney U-test results

\begin{tabular}{|l|c|c|c|c|}
\hline & $\begin{array}{c}\text { The smell was relevant to } \\
\text { what I was watching }\end{array}$ & $\begin{array}{c}\text { The smell heightened the } \\
\text { sense of reality whilst } \\
\text { watching the video }\end{array}$ & The smell was distracting & $\begin{array}{c}\text { I enjoyed watching the } \\
\text { video clip }\end{array}$ \\
\hline $\mathbf{Z}$ & -6.747 & -5.065 & -2.767 & -3.983 \\
\hline $\mathbf{p}$ & .000 & .000 & .002 & .000 \\
\hline
\end{tabular}

Once this was established, the results from the investigative study were further analyzed using the repeated measures ANOVA test to show the influence of content, i.e. the six different video categories, and the influence of association between olfactory media and audiovisual content, i.e. differences between the two study groups, on the user-perceived experience.

Last but not least, odor perception profiles will also be created (as described in the next section) and their subsequent impact on the perceived experience of the olfaction-enhanced multimedia will be analyzed using the Kruskal-Wallis $\mathrm{H}$-test, a non-parametric suitable for showing if significant differences exist between the different profile groups.

\subsection{Odor Perception Profiles and their Impact on the User-Perceived Experience}

In order to analyze participants' responses to questionnaire statement 7 , which asks participants to 'choose which smell category best describes the nature of the smell released during the video clip', we created odor perception profiles. These odor perception profiles are 'Know what they smelt', 'Smelt what they saw' and 'Have no clue what was smelt' and we discuss how we arrived at these profiles first before discussing their subsequent impact on the user-perceived experience below.

The six smells used in the experiments were Burning Wood, Wallflower, Strawberry, Rubbish Acrid, Cedar Wood and Curry. Participants were required to pick one of the following nine options that they thought best described the nature of the smell they had perceived whilst watching the multimedia video clips:
- stale
- flowery
- burnt
- garlicky
- spicy
- fruity
- woody
- foul
- malty (cereal)

We provided a few more options than our six smell categories to make identification somewhat easier for participants because findings from previous research (Dubois and Rouby, 2002; Issanchou et al., 2002; Köster, 2002) have indicated that individuals often find it more difficult to name odors perceived than to recognize them. For this reason, more often than not, people will identify an odor by naming it after something familiar that it reminds them of. Participants were also able to choose the option, 'Did not detect 
any smell', but these responses were excluded from the analysis. Thus, in our analysis of participants' responses we took into consideration the following:

- Burning wood can be described as a compound scent made up of burnt and woody odors, so in this case we considered the responses 'burnt' and 'woody' as being correct for describing this smell.

- The word stale is used to describe something that has lost its freshness, e.g. stale air and stale bread, and thus we considered stale, as well as foul, to be an acceptable response for the Rubbish acrid scent.

- In the case of the curry scent, we accepted both spicy and garlicky as suitable options for describing the smell. Curry is cooked differently by most cultures, thus making the aroma it produces different depending on the ingredients used and the way it is cooked. As such, we accepted the latter option as a suitable response because garlic is associated with spicy cooking.

Accordingly, using participants' responses to questionnaire statement 7 , that is, their perception of what they felt they smelt and taking into consideration these points, we arrived at the following three odor perception profiles:

- Know what they smelt: participants who were able to correctly identify the smell emitted regardless of the accompanying audiovisual content

- Smelt what they saw: participants whose perception of the perceived odor was influenced by the accompanying audiovisual content

- Have no clue what was smelt: here, the response by the participant indicates that $\mathrm{s} / \mathrm{he}$ did not have the faintest idea of what they smelt. Based on the discussions above on odor familiarity, there is also a slight possibility that responses in this category may have been as a result of participants recognizing the odor, but being unable to identify it and subsequently named the odor incorrectly. Table III below shows which of these categories apply to the experimental and to the control studies and the numerical, ordinal rating assigned to each category.

Table III: Odor perception profiles

\begin{tabular}{|l|c|c|c|}
\hline & Rating & Applies to Experimental Study & Applies to Control Study \\
\hline Know what they smelt & 3 & $\mathrm{x}$ & $\mathrm{X}$ \\
\hline Smelt what they saw & 2 & $\mathrm{x}$ & $\mathrm{X}$ \\
\hline Have no clue what they smelt & 1 & $\mathrm{x}$ & \\
\hline
\end{tabular}

Using these odor profiles, we employed the Kruskal-Wallis H-test, suitable for non-parametric data, and determined that the opinions between participants in the different perception profiles were significantly different between the groups (Table IV).

Table IV Kruskal-Wallis H-test results

\begin{tabular}{|l|c|c|c|c|}
\hline & $\begin{array}{c}\text { The smell was relevant to } \\
\text { what I was watching }\end{array}$ & $\begin{array}{c}\text { The smell heightened the } \\
\text { sense of reality whilst } \\
\text { watching the video }\end{array}$ & The smell was distracting & $\begin{array}{c}\text { I enjoyed watching the } \\
\text { video clip }\end{array}$ \\
\hline $\mathbf{X}^{2}$ & 18.290 & 14.341 & 7.397 & 16.090 \\
\hline $\mathbf{p}$ & .000 & .001 & .025 & .000 \\
\hline
\end{tabular}

In the following sections we further analyze participants' perception of the association between olfactory media and audiovisual content and the influence it subsequently had on their perception of the olfactionenhanced multimedia experience.

\subsection{Impact of Associating Smell with Content on the Perceived Sense of Relevance of the Olfactory Media}

In this section, we measure the impact that the use of mismatched scents, i.e. combining unrelated olfactory media content with audiovisual media content, in olfaction-enhanced multimedia have on a users' perception of the sense of relevance. In other words, will users notice that the combined media objects are not semantically related? Analysis was based on participants' agreement, on a scale of 1 to 5 , with the questionnaire statement - 'The smell was relevant to what I was watching'. Accordingly, we conducted a repeated measures ANOVA test to investigate the influence of the use of wrongly associated scents on participants' perception of the sense of relevance of the olfactory media in our olfaction-enhanced multimedia videos. The results from this test are shown in Table V. 
Table V: Influence of associating smell with content on the perceived sense of relevance of the olfactory media

\begin{tabular}{|l|c|c|c|}
\hline \multicolumn{2}{|l|}{ GLM Repeated Measures Test } & F & Sig. \\
\hline Within-Subjects Effects & Video & 3.989 & 0.002 \\
\hline Within-Subjects Effects & Video * Association & 3.733 & 0.003 \\
\hline Between-Subjects Effects & Association & 42.965 & 0.000 \\
\hline
\end{tabular}

The results from the repeated measures ANOVA test show that the effects of the two factors under consideration, as well as the interaction effects between them are statistically significant. Thus, as previous research (Ghinea and Thomas, 1998; Jumisko-Pyykkö et al., 2007) and the results from the earlier experiments reported in this research work have shown (Ghinea and Ademoye 2010; Ghinea and Ademoye, in press) content has a significant impact on users' perception of multimedia ( $F=3.989$, $\mathrm{p}=0.002$ ). More importantly, however, the association between olfactory media content and audiovisual content in the olfaction-enhanced videos was also found to be significant, and consequently impacts on the perceived sense of relevance of the olfactory media $(F=42.965, p=0.000)$. In addition, these results also show that the influence of associating smell with content on the perceived sense of relevance of the olfactory media depends on content $(F=3.733, p=0.003)$. Figure 3 depicts the mean opinion values relating to these results, and we use them to discuss further patterns observed.

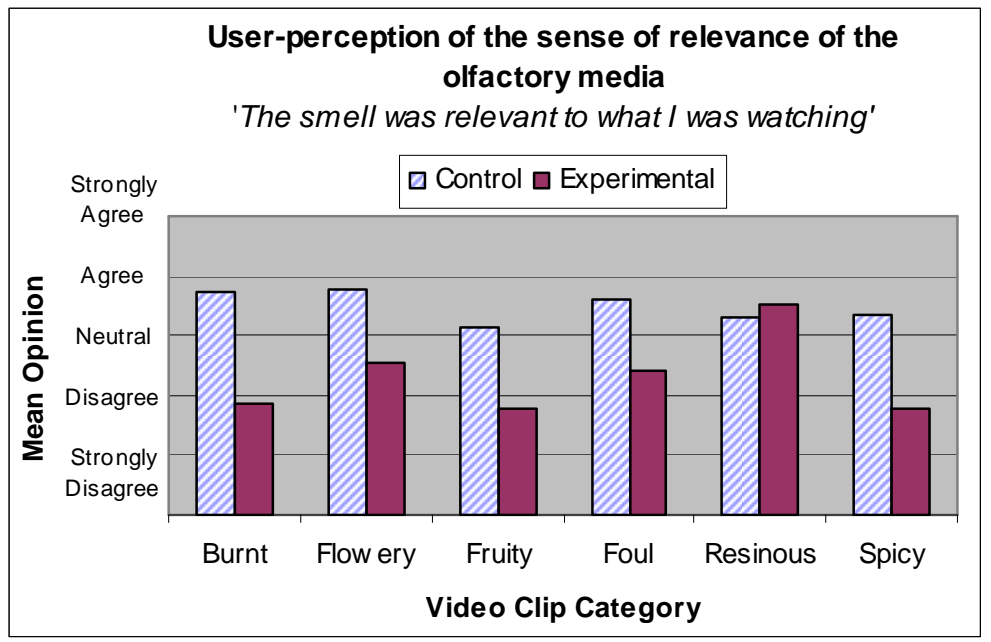

Figure 3: Mean opinion scores (MOS) reflecting participants' perception of the sense of relevance of the olfactory media

With the exception of the Resinous video clip, the mean opinion values are much higher for the control study group compared to the experimental study group. Thus, as is expected, the perceived sense of relevance is greater when correctly associated scents, i.e. relating to the content, are used as opposed to when mismatched scents are used. Moreover, participants did notice the mismatch, as the mean opinion values show that participants from the experimental study group mostly disagreed, or were ambivalent, in their opinions that the unrelated scents released were relevant to what was watched.

However, in the case of the Resinous video clip, not only did participants in the experimental study group slightly agree that the mismatched scent was relevant to what was watched, but they also appear to have found the mismatched smells used more relevant than the control study participants (who incidentally had more of an ambivalent opinion in this respect). This exception may be attributed to the fact that classes of odors are not clearly delineated (Chastrette, 2002), and as such, participants may have also found some of the mismatched scents, so to speak, also relevant to this video. This plausible explanation is further strengthened by the fact that when participants in the experimental study group were asked to choose a smell category that they thought would have been best suited for the video clips, the Resinous video clip produced the widest variety of responses (see section 4.6). 
Table VI: Mean opinion scores (MOS) reflecting odor profile groups perception of the sense of relevance of the

\begin{tabular}{|l|c|c|c|c|c|c|}
\hline Profile Group & Burnt & Flowery & Fruity & Foul & Resinous & Spicy \\
\hline $\begin{array}{l}\text { Have no clue what } \\
\text { was smelt }\end{array}$ & 2.40 & 3.25 & 2.08 & 3.10 & 3.47 & 2.11 \\
\hline Smelt what they saw & 3.33 & 3.80 & 4.00 & 3.60 & 4.25 & 2.88 \\
\hline Know what was smelt & 3.20 & 3.62 & 3.22 & 3.33 & 3.55 & 3.14 \\
\hline
\end{tabular}

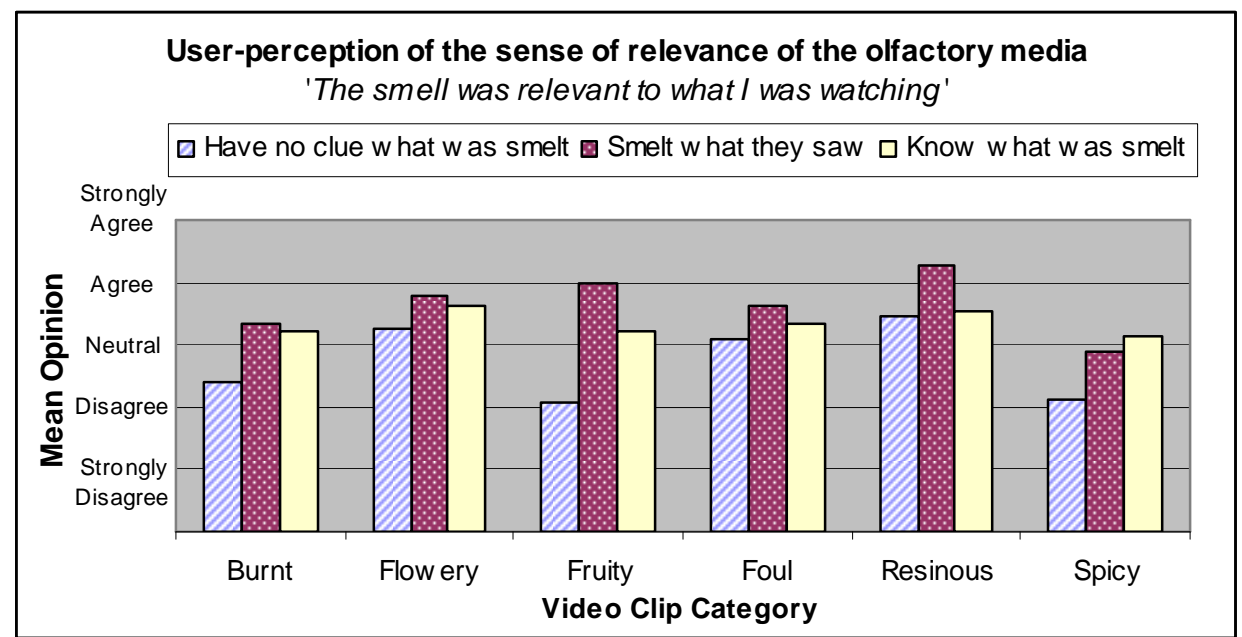

Figure 4: Mean opinion scores (MOS) reflecting odor profile groups perception of the sense of relevance of the olfactory media

As far as the sense of relevance of the olfactory media for each of the odor perception profile groups is concerned, Table $\mathrm{VI}$ and Figure 4 show the breakdown of the mean opinion score values for each video clip viewed. These show that the perceived sense of relevance of the olfactory media was greater for those who smelt what they saw than for the other two odor perception profiles, and as such, emphasizes the role that vision plays in odor perception. Not surprisingly, those who had no clue what was smelt disagreed the most in their opinion that the olfactory media released during the multimedia video clips was relevant. Nonetheless, participants belonging to the 'Smelt what they saw' and 'Know what was smelt' odor perception profiles generally agreed that the olfactory media was relevant to what was watched, while those belonging to the 'Had no clue what was smelt' profile were mostly neutral in their opinion towards the sense of relevance of the olfactory media.

4.3 Impact of Associating Smell with Content on the Perceived Sense of Reality of the Olfactoryenhanced Media

A repeated measures ANOVA test (Table VII) on participants' responses to the statement 'The smell heightened the sense of reality whilst watching the video' revealed that both content $(F=2.591, p=0.026)$ and the association between olfactory media and content $(F=30.195, p=0.000)$ had a significant influence on participants' perception of the sense of reality of the multimedia video clips. Furthermore, the interaction between both factors was also statistically significant $(F=2.420, p=0.036)$, which shows that there is a combined influence of content and smell association on the perceived sense of reality.

Table VII Influence of associating smell with content on the perceived sense of reality of the olfaction-enhanced clips

\begin{tabular}{|l|c|c|c|}
\hline \multicolumn{2}{|c|}{ GLM Repeated Measures Test } & F & Sig. \\
\hline Within-Subjects Effects & Video & 2.591 & 0.026 \\
\hline Within-Subjects Effects & Video * Association & 2.420 & 0.036 \\
\hline Between-Subjects Effects & Association & 30.195 & 0.000 \\
\hline
\end{tabular}

As far as the mean opinion values of participants' opinions (Figure 5) obtained in the study is concerned, surprisingly, the results for the Resinous video clip are similar to what was obtained in the case of analyzing the effect of associating smell with content on participants' perception of the sense of relevance of the olfactory media discussed above. As such, this further confirms the possibility that some 
of, or even all, the mismatched scents used for the Resinous video clip created a greater perceived sense of reality than the scent we considered to be the most appropriate to use for this video, i.e. Cedar Wood. Moreover, participants in the control study were also more neutral in their opinion that this scent heightened the sense of reality of this video clip. It is also possible that participants did not find the Cedar Wood scent as familiar as the other scents used in the experiment.

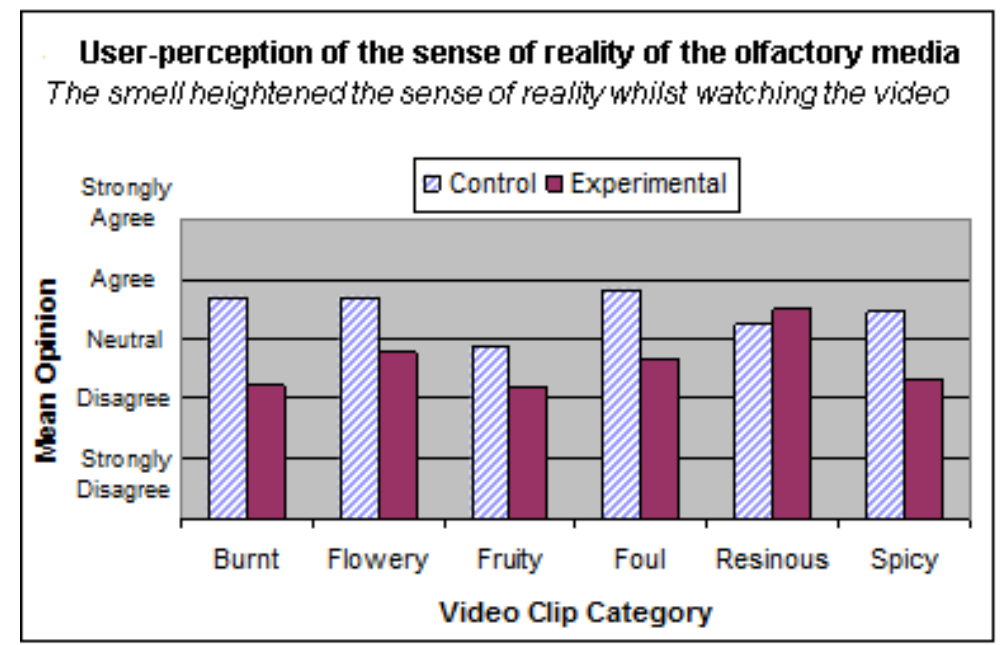

Figure 5 Mean opinion scores (MOS) reflecting participants' perception of the sense of reality of the olfaction-enhanced multimedia videos

Results of a one-way ANOVA test revealed that there was a significant difference in the perceived sense of reality of the olfaction-enhanced multimedia video clips for the different odor perception profile groups $(F=6.628, p=0.002)$. Furthermore, the mean opinion scores for the different clips (Figure 6$)$ show that with the exception of the 'Had no clue what was smelt' profile group, participants belonging to the two other groups mostly had neutral and positive perceptions of the sense of reality of the olfaction-enhanced video clips. However, the mean opinions do not reveal consistent patterns of profile group opinions across the different video categories. For example, for the Flowery, Fruity and Resinous video clips, participants who fell in the 'Smelt what they saw' category had a higher perception of the sense of reality of the olfaction-enhanced videos. However, in the case of the Spicy video clip, it was participants belonging to the 'Know what was smelt' group that had the more positive opinions. Also, the perceived sense of reality was very similar for the three odor profile groups in the case of the Burnt and Foul video clips.

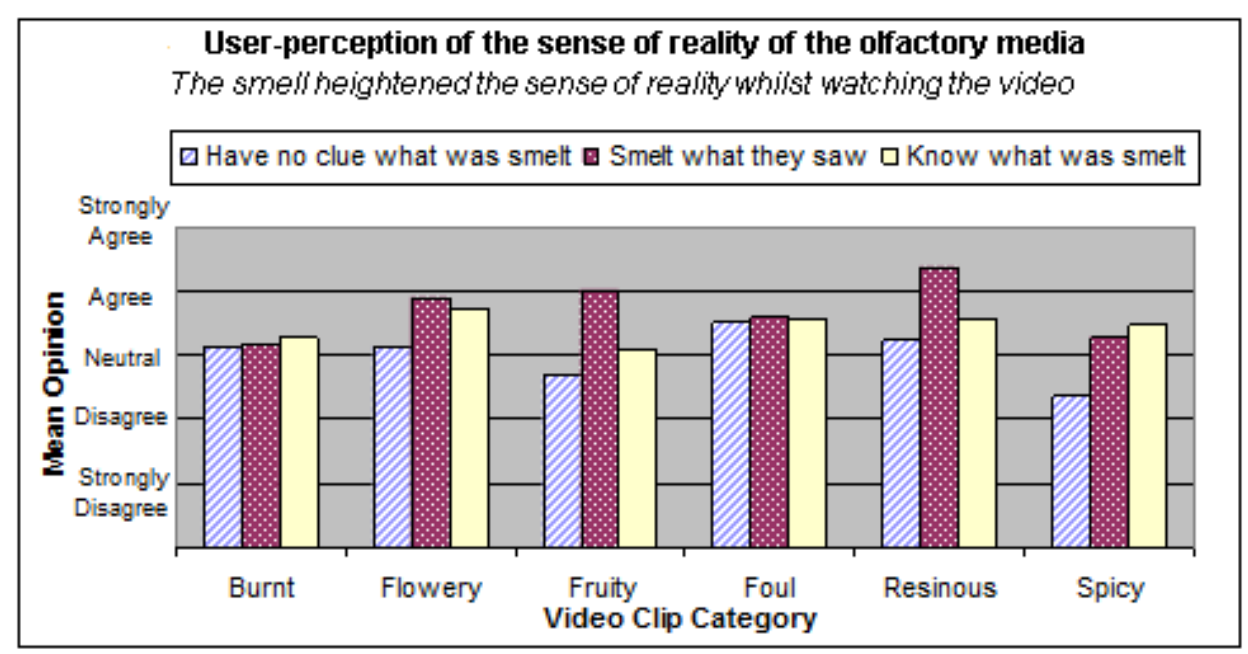

Figure 6: Mean opinion scores (MOS) reflecting odor profile groups' perception of the sense of reality of the olfaction-enhanced videos 


\subsection{Impact of Associating Smell with Content on Acceptability of the Olfactory Media}

We consider the user acceptability of the olfactory media from the perspective of how distracting participants found the use of unrelated scents in the olfaction-enhanced video clips. Analysis is based on participants' responses to the questionnaire statement, 'The smell was distracting'. The results from the repeated measures ANOVA test conducted are shown in Table VIII.

Table VIII: Influence of associating smell with content on the perceived level of distraction of olfactory media

\begin{tabular}{|l|c|c|c|}
\hline \multicolumn{2}{|l|}{ GLM Repeated Measures Test } & F & Sig. \\
\hline Within-Subjects Effects & Video & 2.404 & 0.038 \\
\hline Within-Subjects Effects & Video * Association $^{\prime}$ & 2.959 & 0.013 \\
\hline Between-Subjects Effects & Association & 0.083 & 0.775 \\
\hline
\end{tabular}

We will consider the results of the repeated measures ANOVA test in respect of how distracting participants found the olfactory media data associated with the multimedia video clips first. These results show that while content, as defined by video category, had a significant impact on how distracting participants found the smells associated with each corresponding video $(F=2.404, p=0.038)$, the association of smells and content had no significant influence on the level of distraction the olfactory media caused $(\mathrm{F}=0.083, \mathrm{p}=0.775)$. Additionally, the combined effect of video clip and scent association was also shown to be statistically significant $(F=2.959, p=0.013)$. As these results have only highlighted whether or not there were any significant difference in the perceived level of distraction between participants and across video categories, we use the mean opinion score values (shown in Figure 7 ) to show the general perceived opinion.

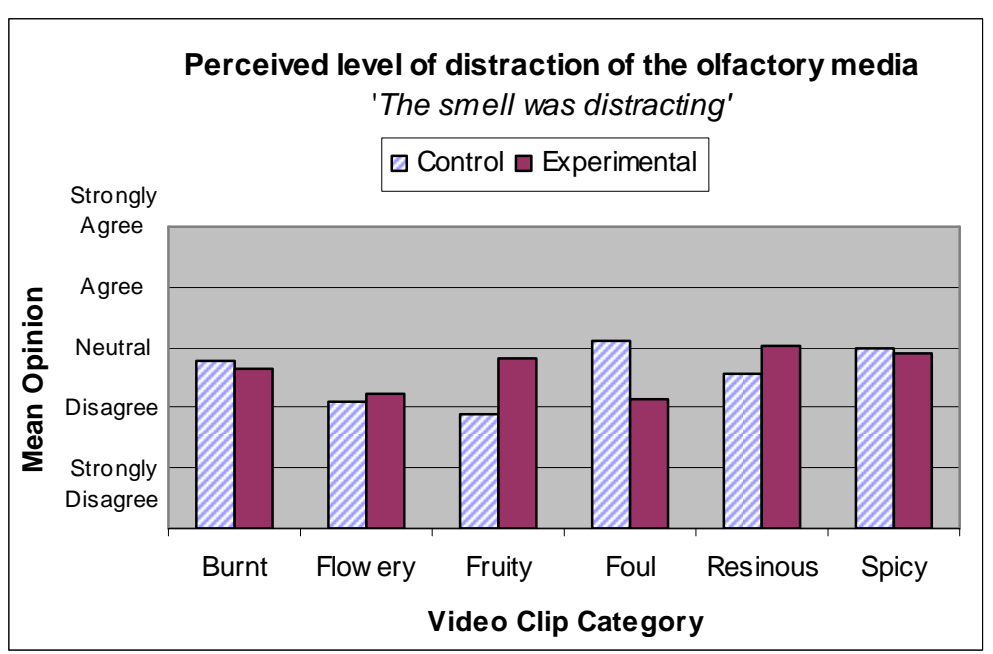

Figure 7: Mean opinion scores (MOS) reflecting participants' perception of how distracting the olfactory media associated with the videos was

The mean opinion score values show that for the Flowery, Fruity and Resinous video clips, participants in the control study group found the related smells used less distracting than those in the experimental study group, who watched the video clips with unrelated smells. Generally, however, participants had a neutral opinion or did not find the olfactory media distracting in either case, that is, when related or unrelated smells were combined with the multimedia video clips. For three out of the six video clips, i.e. Burnt, Flowery and Spicy, the mean opinion scores were quite comparable for the control study and experimental study participants. In the case of the Foul video clip, participants found the related Rubbish Acrid scent used for the control study group more distracting than the unrelated smells used in the experimental study cases. 


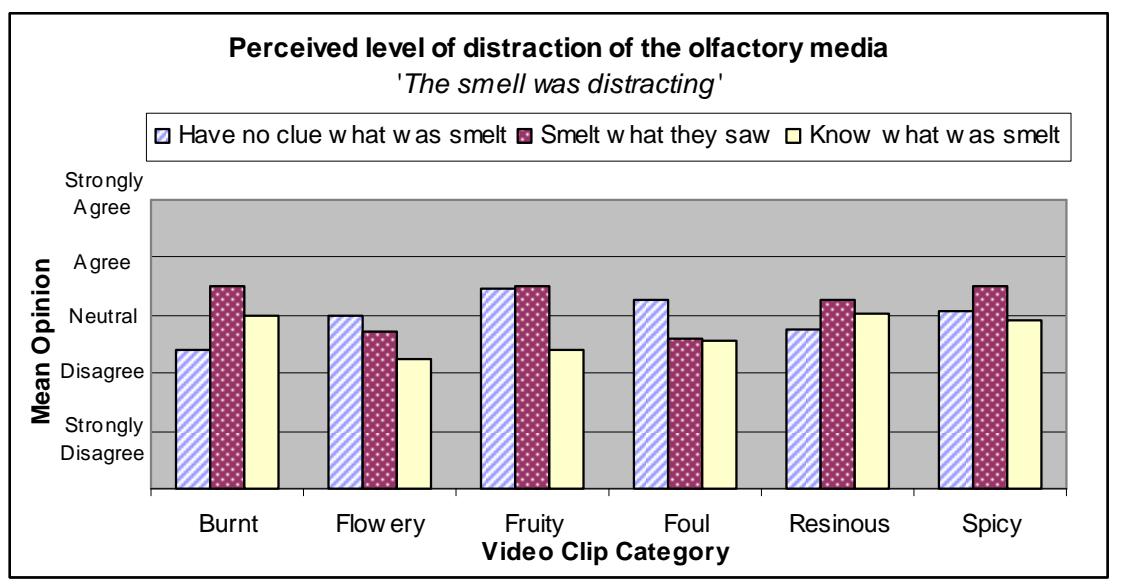

Figure 8: Mean opinion scores (MOS) reflecting odor profile groups' perception of how distracting the olfactory media videos was

As regards the distribution of scores among the various odor perception profiles, the mean opinion values for the different video clip categories (Figure 8) generally reflect that opinions of the different profile groups ranged from slight disagreement to slight agreement on how distracting the olfactory media was. It was also a mixed pattern of responses, with participants who 'Smelt what they saw' finding the olfactory media more distracting for 4 out of the 6 videos viewed and those who 'Had no clue what was smelt' finding it more distracting for the other 2 video clips. Participants who 'Knew what was smelt' found the olfactory media the least distracting.

\subsection{Impact of Associating Smell with Content on User Enjoyment of the Multimedia Experience}

To consider the impact of associating smell with content on participants' enjoyment of the olfactionenhanced multimedia experience, we analyze their responses to the questionnaire statement - I enjoyed watching the video clip'. Responses indicated their level of agreement with this statement on a scale of 1 to 5. Results of the repeated measures ANOVA test conducted in this respect are shown in Table IX and these results are significant for the two factors considered and the interaction between them. Thus, the association between olfaction and content $(F=30.195, p=0.000)$, and content $(F=2.591, p=0.026)$, had a significant impact on participants' enjoyment of the multimedia experience. In addition, the results also show that influence of the use of related, or unrelated scents, depends on content ( $F=2.420, p=0.036)$.

Table IX: Influence of associating smell with content on the enjoyment of the multimedia experience

\begin{tabular}{|l|l|c|c|}
\hline GLM Repeated Measures Test & F & Sig. \\
\hline Within-Subjects Effects & Video & 2.591 & 0.026 \\
\hline Within-Subjects Effects & Video *Association & 2.420 & 0.036 \\
\hline Between-Subjects Effects & Association & 30.195 & 0.000 \\
\hline
\end{tabular}

Figure 9 presents the mean opinion score values obtained in respect of the perceived enjoyment of the multimedia video clips for both study groups. These show that although generally participants enjoyed the olfaction-enhanced multimedia experience, the level of enjoyment was significantly (as shown in Table IX) higher in the control study case when related smells were associated with the multimedia video clips. 


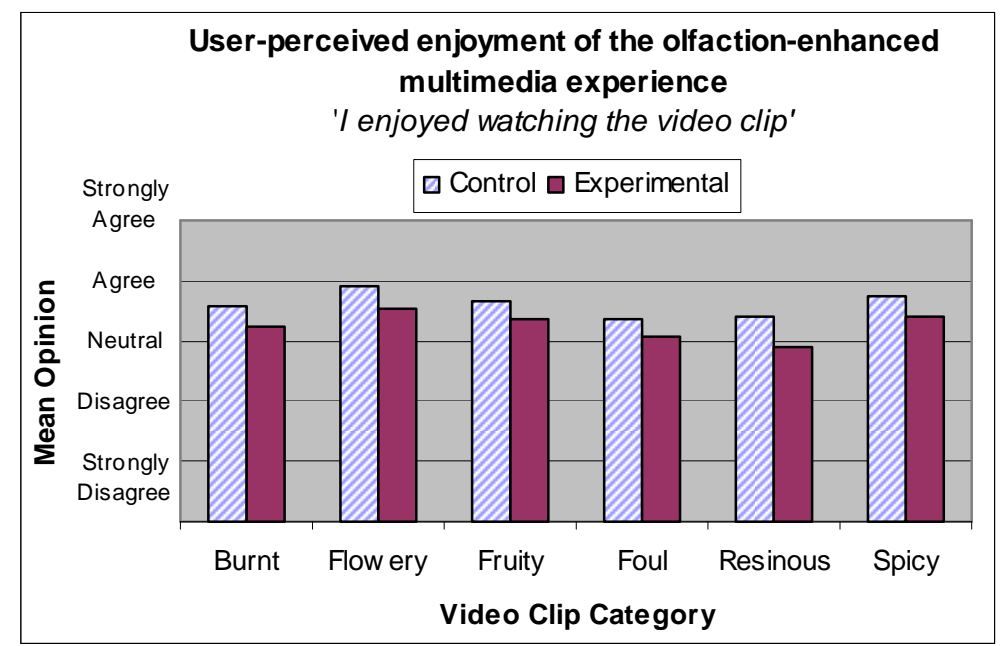

Figure 9: Mean opinion scores (MOS) reflecting participants' perceived enjoyment of the olfaction-enhanced multimedia experience

Participants, however, had a more neutral opinion with regards to the enjoyment of the Foul and Resinous video clips viewed in the experimental study case. Thus, as the ANOVA tests results revealed, the combination of unrelated scents and less engaging subject matter possibly had a detrimental effect on participants' enjoyment of these particular multimedia video clips.

Moreover, the mean opinion values shown in Figure 10, reveal that participants belonging to the 'Know what was smelt' profile group enjoyed the multimedia experience slightly more than the other groups. In addition, participants profiled as 'Having no clue what was smelt' appeared to enjoy the experience more than those profiled as 'Smelling what they saw'.

Generally, those who 'Had no clue what they smelt' had a slightly positive opinion in respect of their enjoyment of the multimedia experience, while the 'Smelt what they saw' profile group displays a mix of opinions across the videos. For the Foul and Resinous video clips, those who 'Smelt what they saw' generally had a more negative opinion towards the enjoyment of the multimedia experience, were neutral in the case of the Burnt and Spicy video clips, and slightly positive in the other cases. In the case of the Foul and Resinous video clips, it is not surprising that those who 'Smelt what they saw' had a more negative opinion as regards their enjoyment of these video clips. Profiled as 'Smelling what they saw' already suggests that the visual sense played a very dominant role in the participants perception of these clips. For the Foul video clip, participants had to watch a bowl of fruit rot away, while the Resinous video clip was a documentary focused on Eastern Red Cedar trees responsible for spring-time allergies.

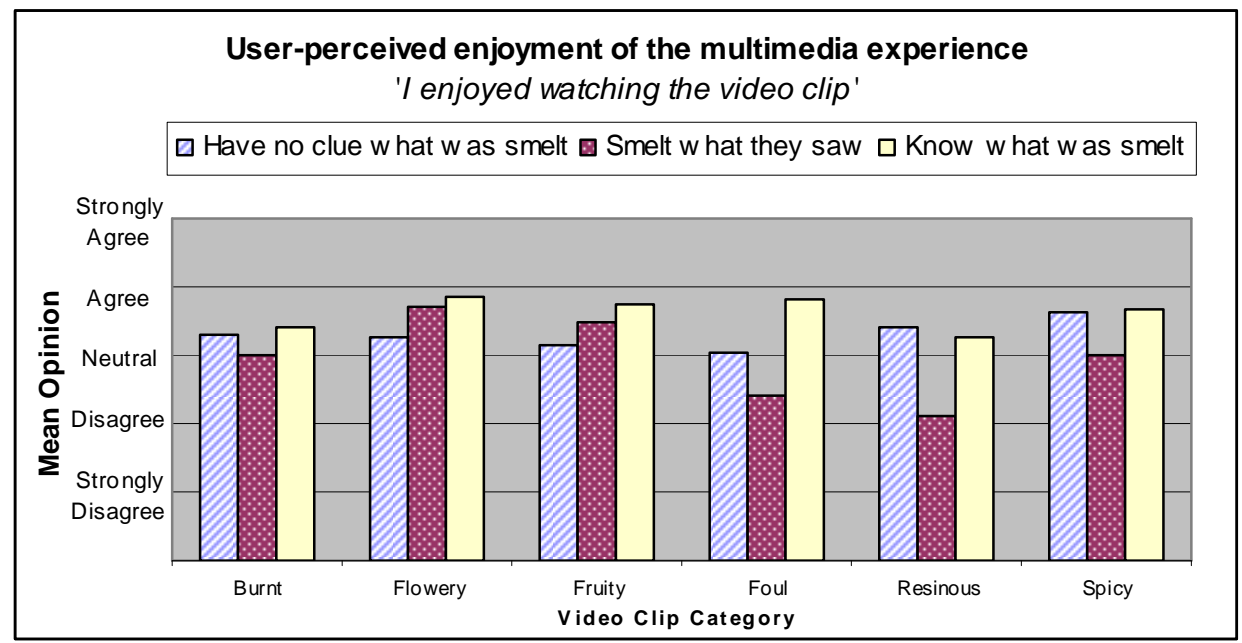

Figure 10: Mean opinion scores (MOS) reflecting odor profile groups perception of how enjoyable they found the multimedia experience 


\subsection{Scented Audiovisual Association Recommended by Participants}

Finally, we asked participants in the experimental study to recommend what scent they thought would be most suitable to create an olfaction-enhanced experience for each of the videos watched. Participants' recommendations are based on their responses to questions 9 and 10 of the questionnaire and are summarized in Table X.

Table X: Scented audiovisual association as recommended by participants

\begin{tabular}{|l|c|c|c|c|c|c|c|c|}
\hline & Burnt & Flowery & Foul & Fruity & Garlicky & Spicy & Stale & Woody \\
\hline Burnt & 21 & & 1 & & & & & 3 \\
\hline Flowery & & 22 & & 3 & & & & \\
\hline Fruity & & & & 24 & 1 & & & \\
\hline Foul & & & 13 & 7 & & & 5 & \\
\hline Resinous & & 8 & 1 & 1 & 1 & 1 & 2 & 11 \\
\hline Spicy & & & & & 6 & 19 & & \\
\hline
\end{tabular}

It is not surprising to see that these recommendations also further confirm that participants generally do not want to have to perceive unpleasant smells in an olfaction-enhanced display, even if the unpleasant smell is more related to the other content it is being combined with. Looking at the recommendations for the Foul and Resinous video clips, participants have suggested that pleasant smells such as fruity and flowery odors would have been most appropriate to use despite the fact that the more predominant subject matter does not relate to these pleasant smells. One participant even went as far as saying that the emitted smell for the Foul video "could have smelt like rotten fruit, but that wouldn't have been nice". The Resinous video clip provided the most varied responses. Nonetheless, it must be remarked that the recommendations by participants show that generally our selection of scents to associate with the videos in the control study experiment was mostly appropriate.

\section{CONCLUDING DISCUSSION}

The experiment reported in this paper aimed to discover the effect the association between olfactory data and audiovisual content has on the user-perceived experience of olfaction-enhanced multimedia applications. In order to achieve this, we varied olfactory media content association by combining our video excerpts with semantically related and unrelated scents, and subsequently measured the impact this variation had on participants' perception of the olfaction-enhanced multimedia experience.

Results showed that there was a significant difference in participants' opinions regarding their enjoyment of the multimedia experience when semantically unrelated smells were used as opposed to when semantically related smells were used to enhance the video clips. Furthermore, there was also a significant difference in opinions in respect of the perceived sense of relevance of the olfactory media and its ability to heighten the sense of reality. Generally, the results revealed that participants did not find the semantically unrelated scents relevant to the multimedia video excerpts, and neither were they of the opinion that these scents heightened the sense of reality of the olfaction-enhanced clips. On the other hand, participants' opinions reflected a positive bias towards the related scents used as controls in the same respects, which is consistent with the findings from the two preceding investigative studies, for which semantically related scents were used to augment the multimedia video content. Scent association was also found to have a significant impact on user enjoyment. Participants' opinions were mixed, i.e. slightly positive or ambivalent, as regards their enjoyment of the multimedia experience with unrelated scents, and when compared to the generally more positive opinions when related scents were used in the same respect.

Using our defined odor perception profiles, we observed significant differences between the odor perception profile groups' opinions of the olfaction-enhanced multimedia experience. Results showed that those who generally 'Smelt what they saw' were the most positive in their opinions as regards the sense of relevance of the olfactory media and its ability to heighten the sense of reality of the multimedia video clips. What is however interesting, is that the results reflect that participants belonging to this profile group found the olfactory media the most distracting and, moreover, that they enjoyed the multimedia experience less than their other cohorts. Participants profiled as 'Having no clue what was smelt' generally had an ambivalent attitude towards the olfaction-enhanced multimedia experience. Furthermore, relating our results to research findings that have shown that vision plays a predominant role in odor perception (Blackwell, 1995; Gottfried and Dolan, 2003; Köster, 2002;Morrot et al., 2001; Sakai et al., 2005), our results revealed that most participants in our study 'Knew what was smelt', as indicated by the majority of 
participants falling into this profile group. There were also more participants who 'Had no clue what was smelt' than those who 'Smelt what they saw'.

In summary, the results generally confirm what previous research studies (Chastrette, 2002; Fox, 2007; Issanchou, 2002; Kaye, 2001, 2004; Köster, 2002; Sakai et al., 2005) have highlighted regarding the olfactory sense, even when it may be potentially masked by the presence of other stimuli, namely that:

1. Odor perception varies amongst individuals as shown by the odor perception differences when smells were mismatched, and even matched, with audiovisual content;

2. We are particularly good at discriminating odors and generally poor at odor recognition and identification - although participants were mostly able to tell that the mismatched scents were not relevant to the presentations, they were unable to correctly identify the nature of the mismatch; and

3. The sense of vision does play a role in odor perception as shown by the resulting 'Smelt what they saw' odor profile group when unrelated scents were used to enhance the video clips.

In conclusion, our work has highlighted that for users to consider the added olfactory media relevant to the multimedia experience, as well as having a significant impact on their enjoyment and sense of reality of the experience, they must be able to associate some meaning between the combined olfactory media and other multimedia objects present. Last but not least, the findings also emphasize that there is a degree of importance attached to scents used to augment multimedia, and therefore integrating scents with multimedia is more than just a novelty factor that will soon wear off.

\section{REFERENCES}

Blackwell, L. 1995, "Visual cues and their effects on odor assessment", Nutrition \& Food Science, vol. 95, no. 5, pp. 24-28.

Bodnar, A., Corbett, R. \& Nekrasovski, D. 2004, "AROMA: Ambient awareness through olfaction in a messaging application: Does olfactory notification make 'scents'?", ICMI'04 - Sixth International Conference on Multimodal Interfaces, pp. 183.

Boyd Davis, S., Davies, G., Haddad, R. and Lai, M. 2006. "Smell Me: Engaging with an Interactive Olfactory Game", Proceedings of the Human Factors and Ergonomics Society 25th Annual Meeting, pp. 25-40, UK.

Brewster, S.A., McGookin, D.K. \& Miller, C.A. 2006, "Olfoto: Designing a smell-based interaction", CHI 2006: Conference on Human Factors in Computing Systems, pp. 653.

Chastrette, M. 2002, "Classification of Odors and Structure-Odor Relationships" in Olfaction, Taste, and Cognition, eds. C. Rouby, B. Schaal, D. Dubois, R. Gervais \& A. Holley, Paperback Re-issue edn, Cambridge University Press, New York, USA, pp. $100-116$.

Dinh, H.Q., Walker, N., Hodges, L.F., Song, C. \& Kobayashi, A. 1999, "Evaluating the importance of multi-sensory input on memory and the sense of presence in virtual environments", Proceedings - Virtual Reality Annual International Symposium, pp. 222-228.

Djordjevic, J., Zatorre, R.J., Petrides, M. \& Jones-Gotman, M. 2004, "The Mind's Nose: Effects of Odor and Visual Imagery on Odor Detection", Psychological Science, vol. 15, no. 3, pp. 143-148.

Dubois, D. \& Rouby, C. 2002, "Names and Categories for Odors: The Veridical Label" in Olfaction, Taste, and Cognition, eds. C. Rouby, B. Schaal, D. Dubois, R. Gervais \& A. Holley, Paperback Re-issue edn, Cambridge University Press, New York, USA, pp. 4766.

Fox, K., 2007, The Smell Report - The human sense of smell, Social Issues Research Centre (SIRC). Available: http://www.sirc.org/publik/smell human.html [Accessed: November 06, 2007].

Fragra - An Interactive Olfactory Game System, 2003, IVRC (Inter-collegiate Virtual Reality Contest) www.ivrc.net. Available: http://chihara.aist-nara.ac.jp/ivrc2003/index.html [Accessed: January 11, 2011].

Ghinea, G. \& Thomas, J.P. 1998, "QoS Impact on User Perception and Understanding of Multimedia Video Clips", The Sixth ACM International Conference on Multimedia, ACM Press, New York, NY, USA, pp. 49-54.

Ghinea, G. and Ademoye, O. 2010, "Perceived Synchronization of Olfactory Multimedia ", IEEE Transactions on Systems, Man, and Cybernetics-Part A: Systems and Humans, vol.40, no.4, pp.657 - 663.

Ghinea, G. \& Ademoye, O.A. (forthcoming), "The Sweet Smell of Success: Enhancing Multimedia Applications with Olfaction", accepted for publication, ACM Transactions on Multimedia Computing, Communications and Applications

Gottfried, J.A. \& Dolan, R.J. 2003, "The nose smells what the eye sees: Crossmodal visual facilitation of human olfactory perception", Neuron, vol. 39, no. 2, pp. 375-386.

Gulliver, S.R. \& Ghinea, G. 2006, "Defining user perception of distributed multimedia quality", ACM Transactions on Multimedia Computing, Communications and Applications, vol. 2, no. 4, pp. 241-257.

Issanchou, S., Valentin, D., Sulmont, C., Degel, J. \& Köster, E.P. 2002, "Testing Odor Memory: Incidental versus Intentional Learning, Implicit versus Explicit Memory" in Olfaction, Taste, and Cognition, eds. C. Rouby, B. Schaal, D. Dubois, R. Gervais \& A. Holley, Paperback Re-issue edn, Cambridge University Press, New York, USA, pp. 211-230.

Jones, L., Bowers, C.A., Washburn, D., Cortes, A. \& Satya, R.V. 2004, "The Effect of Olfaction on Immersion into Virtual Environments" in Human Performance, Situation Awareness and Automation: Issues and Considerations for the 21st Century Lawrence Erlbaum Associates, pp. 282-285.

Jumisko-Pyykkö, S., Häkkinen, J. \& Nyman, G. 2007, "Experienced quality factors - Qualitative evaluation approach to audiovisual quality", Proceedings of SPIE - Volume 6507 Multimedia on Mobile Devices 2007, SPIE - The International Society for Optical Engineering, San Jose, CA, USA.

Kaye, J.N. 2001, Symbolic Olfactory Display, Master of Science edn, Massachusetts Institute of Technology, Massachusetts, U.S.A. Available: http://www.media.mit.edu/ jofish/thesis/ [Accessed: January 11, 2011].

Kaye, J.J. 2004, "Making Scents: aromatic output for HCl", interactions, vol. 11, no. 1, pp. 48-61.

Keller, A. \& Vosshall, L.B. 2004, "Human Olfactory Psychophysics", Current Biology, vol. 14, no. 20, pp. R875-R878. 
Köster, E.P. 2002, "The Specific Characteristics of the Sense of Smell" in Olfaction, Taste, and Cognition, eds. C. Rouby, B. Schaal, D. Dubois, R. Gervais \& A. Holley, Paperback Re-issue edn, Cambridge University Press, New York, USA, pp. 27-44.

Mochizuki, A., Amada, T., Sawa, S., Takeda, T., Motoyashiki, S., Kohyama, K., Imura, M. \& Chihara, K. 2004, "Fragra: a visualolfactory VR game", SIGGRAPH '04: ACM SIGGRAPH 2004 SketchesACM Press, New York, NY, USA, pp. 123.

Morrot, G., Brochet, F. \& Dubourdieu, D. 2001, "The Color of Odors", Brain and Language, vol. 79, no. 2, pp. 309-320.

Nakamoto, T. 2005a, "Odor recorder", Sensor Letters, vol. 3, no. 2, pp. 136-150.

Nakamoto, T. 2005b, "Record of dynamic changes of odors using an odor recorder", Sensors and Materials, vol. 17, no. 7, pp. 365383.

Nakamoto, T., Otaguro, S. Kinoshita, M. Nagahama, M. Ohinishi, K., \& Ishida, T. 2008, "Cooking Up an Interactive Olfactory Game Display", IEEE Computer Graphics and Applications, vol. 28, no. 1, pp 75-78.

Richard, E., Tijou, A., Richard, P. \& Ferrier, J.-. 2006, "Multi-modal virtual environments for education with haptic and olfactory feedback", Virtual Reality, vol. 10, no. 3-4, pp. 207-225.

Rowe, L.A. \& Jain, R. 2005, "ACM SIGMM retreat report on future directions in multimedia research", ACM Transactions on Multimedia Computing, Communications, and Applications, vol. 1, no. 1, pp. 3-13.

Sakai, N., Imada, S., Saito, S., Kobayakawa, T. \& Deguchi, Y. 2005, "The effect of visual images on perception of odors", Chemical Senses, vol. 30 SUPPL. 1.

Stevenson, R.J. \& Case, T.I. 2005, "Olfactory imagery: A review", Psychonomic Bulletin and Review, vol. 12, no. 2, pp. $244-264$.

Tijou, A., Richard, E. \& Richard, P. 2006, "Using Olfactive Virtual Environments for Learning Organic Molecules", 1st International Conference on Technologies for E-Learning and Digital Entertainment, Edutainment 2006, pp. 1223.

Washburn, D.A., Jones, L.M., Satya, R.V., Bowers, C.A. and Cortes, A. 2003. Olfactory Use in Virtual Environment Training, Modelling and Simulation Magazine, 2(3).

Received January 2011; revised XXXX XXXX; accepted XXXX XXXX 